\title{
ALCOHOLIC BERI-BERI HEART
}

\author{
BY \\ A. MORGAN JONES AND CRIGHTON BRAMWELL \\ From the Cardiographic Department, Manchester Royal Infirmary \\ Received February 12, 1939
}

Heart failure due to vitamin deficiency has not hitherto attracted much attention in this country. A single case was reported recently by Price (1938) and another by Yudkin (1938). The case that follows illustrates certain features characteristic of the condition.

\section{CASE RePORT}

A man, aged 36, was admitted to the Manchester Royal Infirmary on November 11, 1938, with acute heart failure. The distribution of the æedema was unusual and, in certain respects, resembled that of renal rather than that of cardiac insufficiency. The face was puffy, the eyelids swollen; there was massive œdema of the legs extending to the thighs ; the penis and scrotum were enormously swollen; the abdomen was distended and contained free fluid ; moist sounds were present in the lungs ; there was slight engorgement of the veins of the neck and the liver was palpable.

Swelling of the ankles, which was greatest in the morning and diminished towards evening, had first been noticed only two weeks previously, and shortness of breath on exertion had been present for only ten days. Three months prior to admission the patient had felt perfectly fit, but his friends had remarked on the fact that he had required to pass water surprisingly seldom, considering the large quantities of beer he drank. The other prominent symptoms were anorexia and epigastric pain. These will be referred to later.

On examination of the circulatory system, the heart was found to be greatly enlarged (Fig. 1), the maximal cardiac impulse being situated in the fifth space $4 \mathrm{~cm}$. beyond the mid-clavicular line. On auscultation, there was typical presystolic gallop rhythm with a loud apical systolic murmur. The resting pulse rate was 120 and the rhythm regular. The blood pressure was $160 / 90$ $\mathrm{mm}$. ; but the diastolic endpoint was poorly defined, the sounds gradually diminishing in intensity and a systolic bruit being heard down to a decompressing pressure of $30 \mathrm{~mm}$.

The knee-jerks could be elicited only on reinforcement and the ankle-jerks were absent. There was no sensory loss to pain, light touch, vibration sense, 
or sense of passive movement and position. The urine was acid, with a specific gravity of 1010 : repeated tests failed to show any albumin.

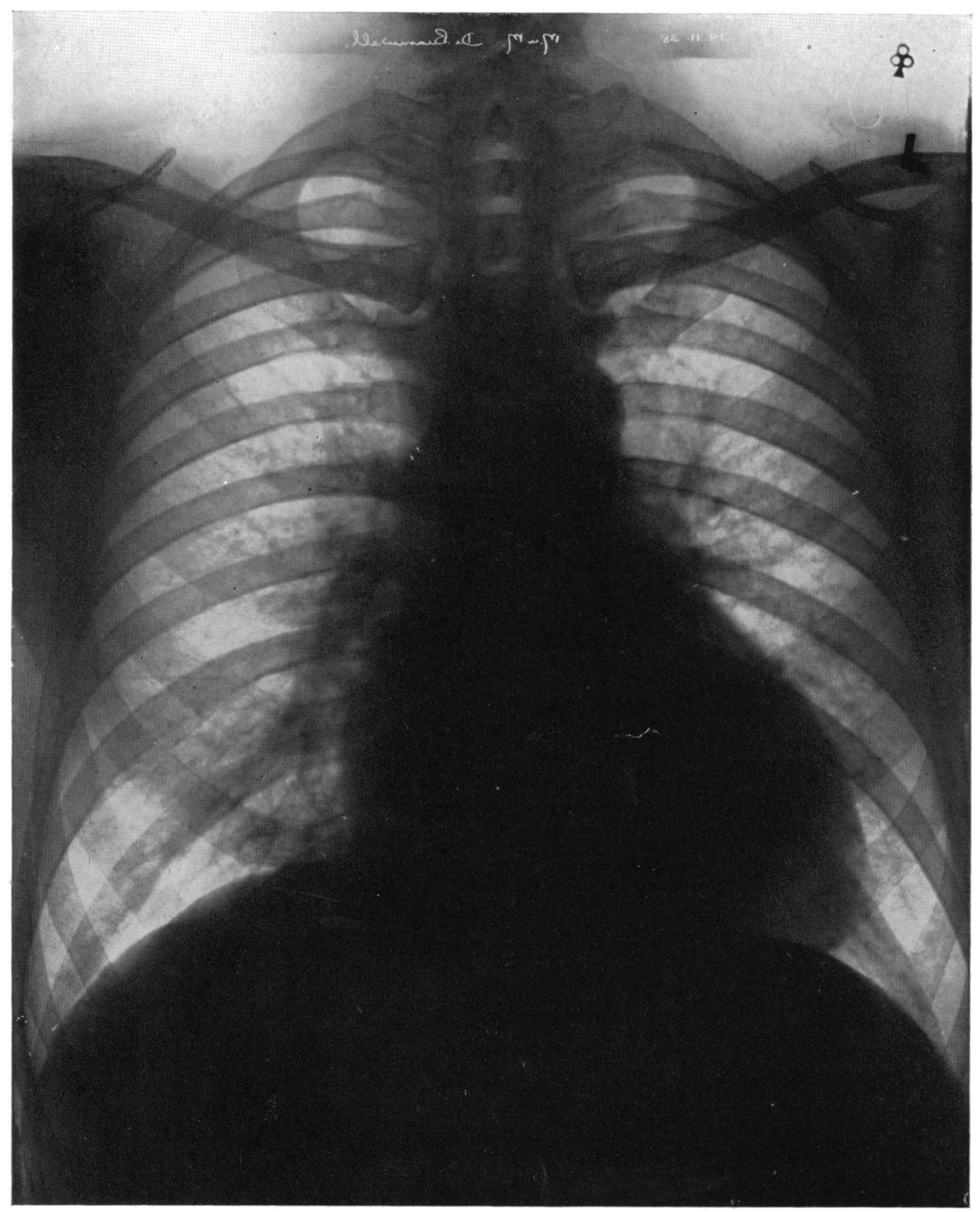

FIG. 1.-Teleradiogram, Nov. 18.

Apart from influenza in 1930, with which he was off work for only one week, there was no previous medical history of significance. He had never suffered from rheumatic fever, sore throats, chorea, scarlet fever, diphtheria, or bronchitis.

Diagnosis.-The clinical picture was atypical. The association of gallop rhythm with extensive œdema, the unusual distribution of the œdema, the 
rapidity with which it had appeared and the fact that, until recently, the patient had been a perfectly healthy man suggested that heart failure, in this case, was not due to any of the usual causes.

In searching for an ætiological factor, the possibility of a vitamin deficiency occurred to us. Further enquiry into the history revealed the fact that for seventeen years, during which time he had been employed as a navvy, he had taken 7 to 8 pints of beer daily.

Eighteen months prior to admission he had become a bar attendant, and since then had taken between 14 and 18 pints of beer every day. He had gradually lost appetite and for the greater part of this period had never had more than one meal a day, and had often gone a whole week without eating any solid food. For six weeks he had vomited after every meal.

Cases of beri-beri, such as occur in the East, are rarely seen in Britain ; but a similar clinical picture may be produced by chronic alcoholism, which many workers consider to be a potent factor in inducing dietary deficiency. It leads to anorexia and so to a deficient food intake ; and, since beer is deficient in vitamin $B_{1}$ (Donovan and Hanke, 1936), the diet becomes deficient in this vitamin content although its caloric value may be adequate, when little other food is taken. Cowgill (1934) has pointed out that one of the first signs of vitamin $\mathbf{B}_{1}$ deficiency is anorexia, which in turn leads to further diminution in vitamin intake. Thus a vicious circle is set up. Alcohol can supply a high caloric value with a very low vitamin content. This is the ideal combination for the development of beri-beri, for the higher the caloric intake the greater is the requirement of vitamin $B_{1}$.

It is interesting to note that the similarity in distribution of the œdema in cases of chronic alcoholism and "beri-beri heart" should have attracted attention before the connecting link between the two conditions was recognized. Writing in 1906, before vitamins had been discovered, Graham Steell referred to the subject in these words :

"Capricious distribution of dropsy is specially apt to occur in cases of the cardiac muscle-failure of beer-drinkers and of the disease known as beri-beri, of both of which diseases, it is curious to note, peripheral neuritis is a clinical feature. ... Curious special localizations of odema met with, in cases of the kind, have been the scrotum, and together the upper trunk, upper extremities, and scalp and neck, so that the œdema simulates that resulting from mediastinal tumour."

Laboratory Investigations. -Electrocardiograms (Fig. 2) showed no significant abnormality. On the third day the T wave in lead III was upright, on the fourteenth day it was almost isoelectric, and a month after admission it was inverted. A similar change was noted by Keefer (1930) in two cases, but it is doubtful whether it is of any significance.

The plasma proteins were not estimated during the acute stage, but ten days after admission the albumin : globulin ratio was $5 \cdot 5: 2 \cdot 0$, and a subsequent determination about seven weeks later gave the ratio $5 \cdot 5: 2 \cdot 1$. On the third day the blood urea was $20 \mathrm{mg}$. per $100 \mathrm{cc}$. and the urea clearance test 67 per 


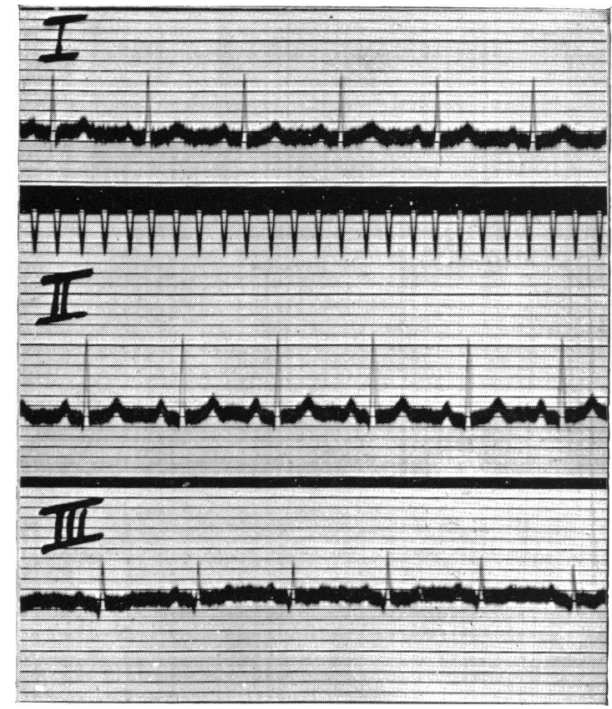

Fig. 2.-Electrocardiogram, Nov. 14. Time intervals, $0 \cdot 2 \mathrm{sec}$. Calibration $2 \mathrm{~cm} .=3 \mathrm{mv}$. A month later $T$ was inverted in lead III.

cent. of the average normal value. A fractional gastric analysis on the fourth day gave a normal result. A blood count on the third day showed :

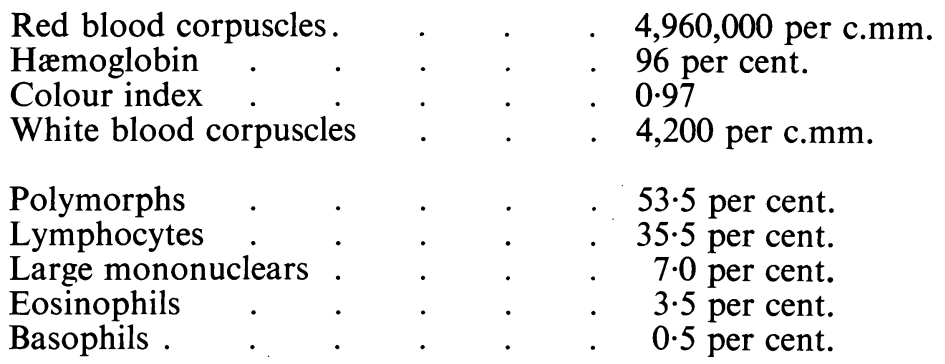

A subsequent count, about seven weeks later, showed slightly higher figures for the red cells and hæmoglobin and the white cells had risen to 6000 with 57 per cent. polymorphonuclears, 35 per cent. lymphocytes, and 3 per cent. eosinophils.

Treatment.-The patient was kept in bed and given daily intramuscular injections of $2 \mathrm{mg}$. of vitamin $\mathrm{B}_{1}$, in the form of Benerva (Roche) ; the total quantity given during the seventeen days he was in hospital being $30 \mathrm{mg}$. Apart from a full diet and Easton's syrup, he received no other treatment.

Progress.-For one day the patient refused all food, but then regained his appetite and ate well. During the first day he passed only 16 ounces of urine ; but about twenty-four hours after the first injection of vitamin $B_{1}$, a brisk diuresis set in, and in the next three days he passed 196 ounces. His weight on admission was $155 \mathrm{lb}$. ; four days later it was $146 \mathrm{lb}$.-a loss of $9 \mathrm{lb}$. On 
admission his pulse rate was 120 ; on the third day it varied between 80 and 90 , and a week later had reached a fairly steady level of 60 to 70 . These values are recorded graphically in Fig. 3. On the fourth day he felt perfectly

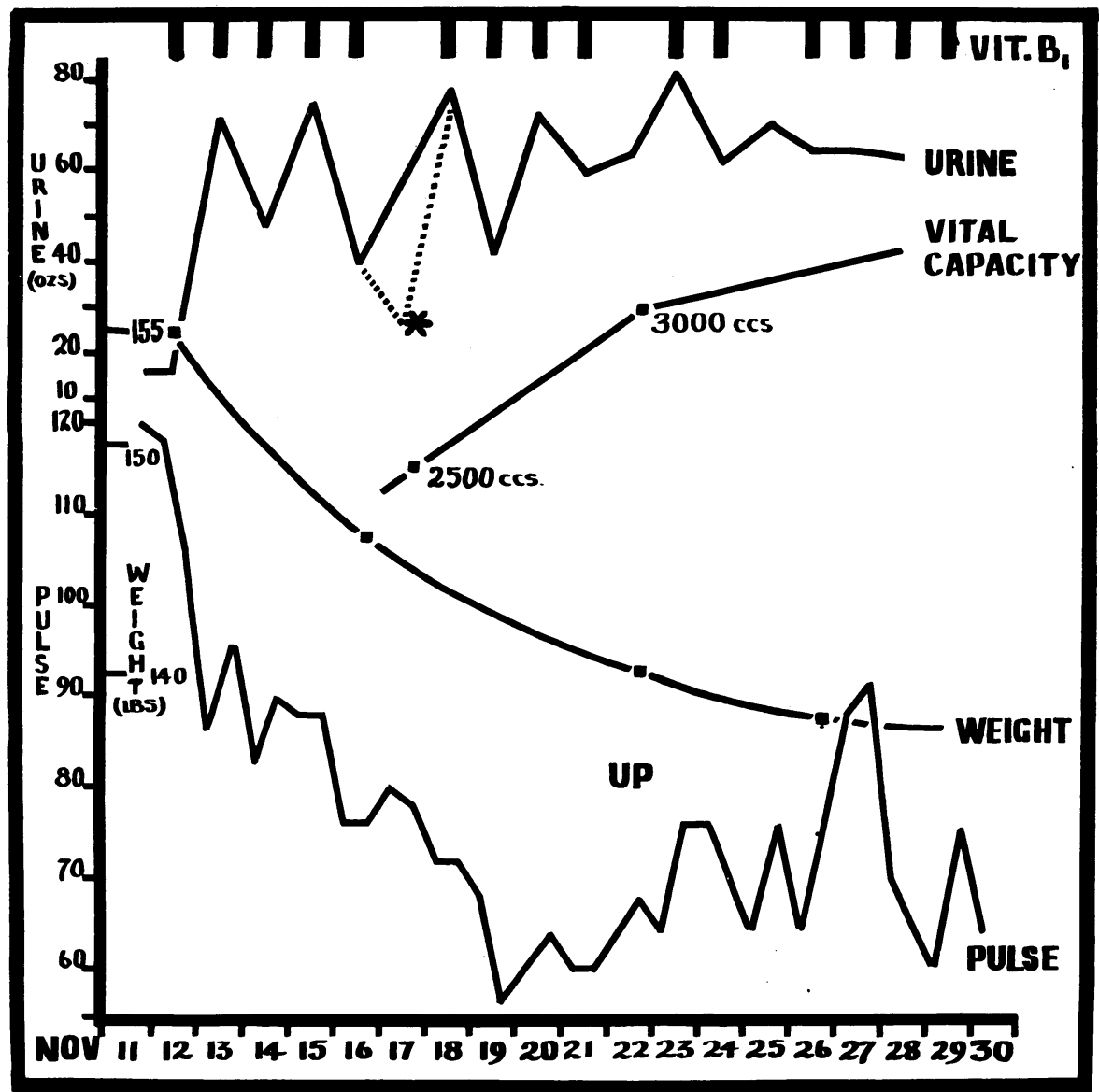

Fig. 3.-Pulse rate, weight, vital capacity, output of urine and dosage of vitamin $\mathbf{B}_{1}$. Each mark at the top of the figure indicates a dose of $2 \mathrm{mg}$. vitamin $\mathbf{B}_{1}$ given intramuscularly. * The whole of the urine was not measured on this date. The vital capacity curve is exterpolated towards a reading taken shortly after the patient was discharged from hospital.

fit, his appetite was excellent, gallop rhythm was no longer present and the œdema had practically disappeared.

The vital capacity on the third day was 2500 c.c. (calculated normal 4175 c.c.) ; five days later it had risen to 3000 c.c. and three weeks after admission it was 3250 c.c. A teleradiogram taken three days after admission showed great cardiac enlargement and considerable pulmonary congestion. Four days later the appearances had altered very little (Fig. 1), but during the next ten days the heart diminished considerably in size (Fig. 4) and the pulmonary congestion completely disappeared.

Ten days after admission he was allowed up and seven days later he was discharged from hospital, since when he has remained fit. 


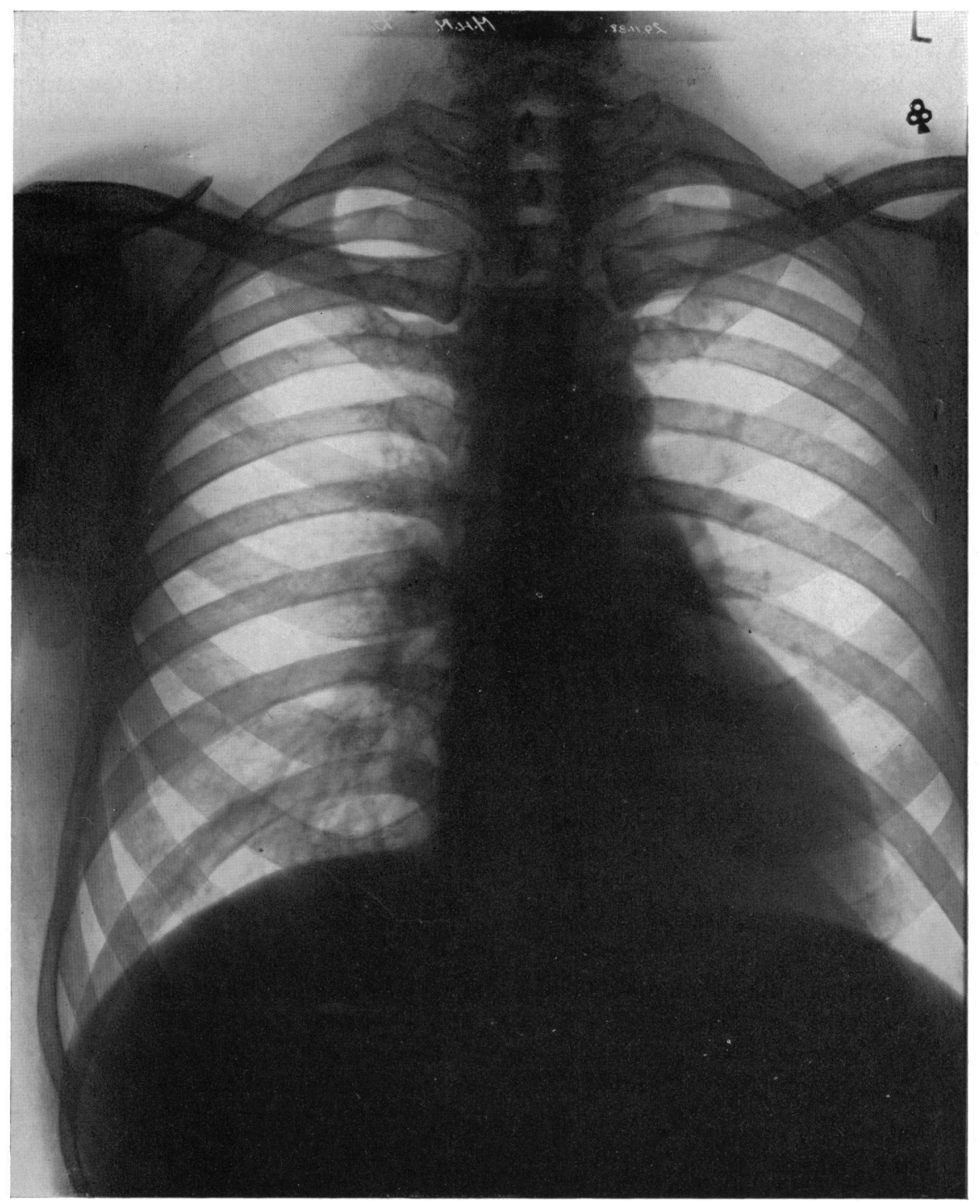

Fig. 4.-Teleradiogram, Nov. 29.

The Beri-Beri Heart

The classical features of " beri-beri heart " as seen in Java were fully described by Aalsmeer and Wenckebach (1928) and later by Wenckebach (1932 and 1934). These workers emphasized the predominant element of right-sided heart failure without pulmonary congestion. Weiss and Wilkins (1936 and 1937a) published a series of 120 cases observed in America, many of which appeared to be attributable to chronic alcoholism. They recorded a large and varied list of signs and symptoms, and stated that the cardiovascular disturbances caused by nutritional deficiency did not form a single rigid clinical syndrome. They 
pointed out the importance of dietary deficiency in precipitating cardiac failure in other forms of organic heart disease.

Hawes (1938) described the clinical picture of "shoshin" (the severe form of acute congestive failure due to beri-beri which is seen in the East) as that of a desperately ill patient, vomiting, breathless and restless, with severe epigastric pain, enlarged heart, dependent œdema, engorged veins, tachycardia, and a low diastolic pressure. This description is almost identical with that given by Aalsmeer and Wenckebach (1928) for what they called the "acute pernicious" beri-beri heart. They divided cardiovascular beri-beri into three groups-a mild ambulatory type with dyspnœa and palpitation; a moderately severe type with cardiac enlargement, œdema and polyneuritis ; and the acute pernicious form described above.

Our case differs from the moderately severe type by the absence of polyneuritis, yet did not present so advanced a clinical picture as the acute pernicious type. It is very similar to the case described by Price (1938) and to one of those reported in detail by Weiss and Wilkins (1936), both of which were attributed to chronic alcoholism.

The absence of signs of polyneuritis is not uncommon in the more severe and acute forms of beri-beri heart, and Keefer (1930), who described 15 cases of beri-beri heart in Japan, showed that the patients who developed cardiac insufficiency were those with least involvement of the nervous system. He regarded this as due to the protection of the heart by the motor disability caused by the polyneuritis. If this hypothesis be correct, we should not expect to find severe signs of polyneuritis in the more acute forms of beri-beri heart, though Strauss (1938) believes that it is rare to find beri-beri heart without at least minimal signs of polyneuritis. Aalsmeer and Wenckebach (1928), on the other hand, think that cardiac enlargement may be detected long before the appearance of the first signs of polyneuritis. Birch and Harris (1934) state that the biochemical lesion caused by vitamin $\mathbf{B}_{1}$ deficiency seems to affect the heart almost immediately and may cause sudden death from heart failure, while its toxic action on the central nervous system proceeds more slowly.

\section{Allied CONDITIONS}

The biochemical mechanism underlying the production of alcoholic beriberi heart is the subject of controversy, and, although deficiency of vitamin $B_{1}$ is of paramount importance, it is possible that this is not the only factor. Before concluding that œdema associated with dietary deficiency is due to lack of vitamin B, other abnormalities in the diet, such as deficiency of proteins or total calories, must be considered, especially when these deficiencies are associated with an increased fluid intake. Such types of deficiency, however, cannot explain the cardiovascular signs and symptoms which are seen in cases like that which we have described, while the plasma protein values reported by Weiss and Wilkins (1936 and 1937a), in cases of alcoholic beri-beri are not sufficiently low to account even for the œdema.

The history in our case naturally led us to speculate on the possible relation 
of alcoholic beri-beri heart to the so-called beer-drinker's heart. This diagnosis is now rarely made ; in fact, the disease seems almost to have died out. This might be accounted for either by the reduced consumption of beer at the present day, or by the fact that beer-drinker's heart is nothing more nor less than hypertensive heart disease. This latter hypothesis receives support from the fact, pointed out by Weiss and Wilkins (1937b), that the disappearance of this disease is chronologically related to the introduction of sphygmomanometry and to the recognition of the importance of hypertension in the production of cardiac hypertrophy and heart failure.

Other forms of œdema associated with dietary deficiency are so-called famine œdema and war œdema. In recent years these conditions have been studied comparatively little ; but most workers believe that they are essentially different from beri-beri. Nixon (1920) regards polyuria, bradycardia and asthenia as the essential clinical features of famine odema; whereas the dyspnœa, tachycardia, cardiac dilatation and signs of heart failure found in association with vitamin $B_{1}$ deficiency are absent. In fact, the only clinical feature common to the two conditions is the odema.

The nature of the dietary deficiency in these conditions has been studied by several workers. Maver (1920) has surveyed the whole field and gives a comprehensive bibliography. She does not believe that war œdema is due to a deficiency of one or more specific vitamins, but that it is the result of a protracted existence on a diet deficient in total calories and especially in protein, and that a high fluid intake and possibly a high salt intake are important accessory factors. She points out that a combination of low calories, low protein and excessive fluid intake will lead experimentally to a severe dropsy corresponding in all respects to war œdema. Cowgill (1934) failed to find any evidence of vitamin $B_{1}$ deficiency in diets under conditions where such œdema might be expected to occur.

The post-mortem appearances were studied by Porter in the Indian famine of 1877-78 (quoted by Nixon, 1920) and are those of starvation. He demonstrated the changes of brown atrophy in the heart ; this is unlike the postmortem findings of Aalsmeer and Wenckebach (1928), and Weiss and Wilkins (1936 and 1937a) in beri-beri heart. These workers found hydropic degeneration and interstitial œdema of the cardiac muscle.

Thus it appears that these forms of œdema are ætiologically, clinically and pathologically distinct from the œdema associated with beri-beri heart.

\section{Diagnosis of the Beri-Beri Heart}

Severe cases of beri-beri heart are rare in this country ; yet their recognition is of importance, for they respond dramatically to specific treatment and very poorly to other measures.

The diagnosis rests essentially upon :

1. The dissimilarity of the clinical syndrome from that of heart failure due to other causes. 
2. The absence of the more common ætiological factors responsible for producing heart failure.

3. The presence of a dietary abnormality compatible with a gross deficiency of vitamin $B_{1}$.

4. The response to treatment with vitamin $B_{1}$.

The diagnosis is corroborated by :

5. The presence of other signs and symptoms of vitamin deficiency.

6. Certain laboratory tests.

1. The Clinical Syndrome.-The distribution of the œdema is unusual. It may be most striking in the face and genitalia, and most pronounced in the morning, suggesting renal rather than cardiac insufficiency; but the absence of albuminuria, the relatively high renal efficiency and the normal protein content of the plasma exclude this diagnosis. In our case there was less venous engorgement than one would expect in view of the extent of the œdema.

The association of gallop rhythm with extensive œdema is unusual in the other types of heart failure, but common in alcoholic beri-beri heart. Weiss and Wilkins (1936) discussed the clinical differences between beri-beri heart as seen in the East and in America, where it is usually due to chronic alcoholism. They emphasized the frequency of combined right and left heart failure in alcoholic beri-beri, whereas in the East right-sided failure is the rule (Aalsmeer and Wenckebach, 1928 ; Wenckebach, 1928) and pulmonary congestion is stated to occur only as a terminal condition (Wenckebach, 1928). In our case the combination of œdema and systemic congestion with gallop rhythm and pulmonary congestion showed that both right and left ventricles had failed.

2. Atiology.-The absence of the more common causes of heart failure first drew attention to our case, and is probably one of the most valuable clinical pointers to the ætiology. There was no evidence of syphilitic, hypertensive or rheumatic heart disease or of heart failure secondary to pulmonary disease.

Other possible causes of cdema must be considered. In beri-beri heart the plasma proteins are sometimes lowered (Weiss and Wilkins, 1936); but usually not to such a level as would account for the œdema. In our case they were normal on the tenth day, and before the weight had reached a steady level. Severe anæmia is unusual in beri-beri heart, although common in other forms of œdema associated with dietary deficiency.

(3) Diet.- In our case, inquiry into the diet revealed a gross abnormality which left no doubt that a vitamin deficiency must have existed for a considerable time. To justify the assumption of a vitamin deficiency it is essential to establish a gross abnormality of this type. In this country chronic alcoholism is the most frequent cause of such a deficiency, and amongst the reported cases attributed to alcoholism are those of Jolliffe and Goodhart (1938), Price (1938) and many of those recorded by Weiss and Wilkins (1936 and 1937a).

(4) Vitamin Therapy.-The therapeutic test is the most convincing diagnostic evidence. Aalsmeer and Wenckebach (1928) thought the effect of vitamin $B_{1}$ to be as specific for beri-beri heart as thyroid extract is for myxœdema. Its 
action is certainly no less dramatic. In our case, twenty-four hours after the first injection the pulse rate fell, the patient regained his appetite and a brisk diuresis set in.

Rapid response to treatment with vitamin $B_{1}$ has been recorded by Weiss and Wilkins (1936), Hashimoto (1937), Strauss (1938) and others. Weiss and Wilkins (1937b) state that, in general, the improvement is most rapid in patients with a severe degree of congestive failure of relatively short duration. Nylin (1937) recorded a case which responded very well to intravenous vitamin $B_{1}$, although complicated by bilateral pulmonary tuberculosis.

It is important to exclude the possibility that other forms of œdema or heart failure might respond to vitamin $B_{1}$ therapy. Weiss and Wilkins (1936) gave doses of 5,10 and $20 \mathrm{mg}$. of crystalline vitamin $B_{1}$ subcutaneously, intramuscularly, and intravenously to two patients with normal cardiovascular systems, and to three with organic heart disease. They found no significant alternations in heart rate, electrocardiograms, arterial pressure, velocity of blood flow, plasma proteins or in the degree of œdema.

(5) Other Signs of Vitamin Deficiency.-These help to corroborate the diagnosis ; for instance, the presence of polyneuritis and heart failure, in an alcoholic subject, suggests the possibility of alcoholic beri-beri. The commonest associated lesions are polyneuritis and gastro-intestinal disturbances, particularly anorexia, epigastric pain, and vomiting. It is not unusual to find achlorhydria in beri-beri heart, as in the case recorded by Price (1938). Other common associated lesions mentioned by Weiss and Wilkins (1936) are pellagroid dermatitis and glossitis.

(6) Special Tests.-(a) The estimation of vitamin $\mathbf{B}_{1}$ in the blood.-This assay has only recently been possible, and, so far as we know, has never yet been made in a case of beri-beri heart ; but there is little doubt that it will prove to be of value in these cases when there is better agreement as to the lower limit of the normal range. Wilkinson and Rowlands (1938) regard the threshold as about $6.5 \mu \mathrm{g}$ per 100 c.c. using the effect of the vitamin on the growth of Phycomyces blakesleeanus (Schopfer's method) as the method of estimation.

(b) The peripheral circulation rate.-Weiss and Wilkins (1937b) state that the combined presence of congestive failure and a relatively or absolutely increased circulation rate is the most outstanding feature of beri-beri heart failure. It would seem, therefore, that the measurement of the peripheral circulation time is an investigation of value when this ætiology is suspected in a case of acute heart failure.

(c) Aalsmeer's Adrenalin Test.-This is regarded by many as a valuable diagnostic aid. It depends upon the rapid fall of diastolic pressure and the exacerbation of symptoms which follow the injection of adrenalin. Weiss and Wilkins (1936) record a case which demonstrates how this effect is striking in the acute stages and less so as the clinical condition improves.

(d) Electrocardiographic changes in the beri-beri heart have been described by many workers (Aalsmeer and Wenckebach, 1928 ; Scott and Hermann, 1928 ; Keefer, 1930 ; Hashimoto, 1937 ; Price, 1938 ; Wenckebach, 1928 ; Weiss and Wilkins, 1936 ; Strauss, 1938 ; and others) ; but these changes are 
often absent, even in cases with advanced heart failure (Aalsmeer and Wenckebach, 1928), and, although the changes are reversible by treatment, they vary widely in character. The only feature of diagnostic value appears to be the shortening of the P-R interval described in a few cases by Aalsmeer and Wenckebach (1928) and by Price (1938). Chopra, Choudhuri, and De (1937) noted similar changes in 40 per cent. of cases of epidemic dropsy in India. It is only where the electrocardiogram shows changes reversible by vitamin $\mathbf{B}_{1}$ therapy that it can be accepted as affording evidence of value in diagnosis. In our case, the electrocardiogram was within normal limits throughout, but the T wave in lead III, which was upright during the acute stage (Fig. 2), became inverted a month later. This was also noted in two cases by Keefer (1930), but we do not attach any significance to this finding.

\section{Lesser Degrees of Vitamin $B_{1}$ Deficiency}

If gross deficiency of vitamin $B_{1}$ can produce such striking cardiovascular disturbances, it seems probable that less severe deficiency, which must be much more common, often passes unrecognized, and may contribute to the development of cardiac failure in patients with rheumatic, syphilitic, or hypertensive heart disease. It is, therefore, important to inquire into the diet of patients with these forms of heart disease, especially when cardiac failure occurs without adequate cause.

Weiss and Wilkins (1937a) state that cardiovascular disturbances attributable to deficiency of vitamin $B_{1}$ occurred in 35 out of 5506 admissions to the Boston General Hospital medical wards during two years. They regard this form of cardiovascular disease as more frequent than congenital heart disease, adhesive pericarditis, hyper- or hypothyroid heart disease and subacute bacterial endocarditis. It is probable that some cases of beri-beri heart escape recognition, and that the heart failure is attributed to other causes.

\section{SUMMARY}

A bar attendant, aged 36, with a history of chronic alcoholism and gross dietary deficiency, with anorexia, vomiting, epigastric pain, extensive œdema, a greatly enlarged heart, gallop rhythm and tachycardia, was treated with parenteral vitamin $B_{1}$. He lost his odema and other signs of cardiac failure in five days, the heart diminished greatly in size, and he was discharged cured seventeen days after admission.

The case is compared with others that have been reported and the diagnosis of the condition is discussed.

We are indebted to our colleague Dr. E. W. Twining for the two radiograms.

\section{REFERENCES}

Aalsmeer, W. C., and Wenckebach, K. F. (1928). "Herz und Krieslauf bei der BeriberiKrankheit." Wien. Arch. in. Med., 16, 193.

Birch, T. W., and Harris, L. J. (1934). Biochem. J., 28, 602. 
Chopra, R. N., Choudhuri, R. N., and De, N. (1937). Indian Med. Gaz., 72, 1.

Cowgill, G. R. (1934). The Vitamin B Requirement of Man. Yale University Press.

Donovan, P. B., and Hanke, M. E. (1936). Proc. Soc. exp. Biol., N.Y., 33, 538.

Hashimoto, H. (1937). Amer. Heart J., 13, 580.

Hawes, R. N. (1938). Reported by Brit. Med. J., 1938, 1, 413.

Jolliffe, N., and Goodhart, R. (1938). J. Amer. Med. Ass., 111, 380.

Keefer, C. S. (1930). Arch. Intern. Med., 45, 1.

Maver, M. B. (1920). J. Amer. med. Ass., 74, 934.

Nixon, J. A. (1920). Clin. J. Bristol med. Soc., 50, 273.

Nylin, G. (1937). Sartryck ur Nordisk Med. Tidsskr., 15,

Porter, (1889). The Diseases of the Madras Famine in 1877-78. Madras Govt. Press, 1889 (quoted by Nixon, 1920).

Price, N. (1938). Lancet, 1, 831.

Scott, L. C., and Hermann, G. R. (1928). J. Amer. med. Ass., 90, 2083.

Steell, Graham (1906). Text-book on Diseases of the Heart, Manchester.

Strauss, M. B. (1938). J. Amer. med. Ass., 110, 953.

Weiss, S. and Wilkins, R. W. (1936). Trans. Ass. Amer. Physicians, 51, 341. (1937a). Ann. intern. Med., 51, 104. (1937b). J. Amer. med. Ass., 109, 786.

Wenckebach, K. F. (1928). Lancet, 2, 265. (1932). Libman Anniversary Vols., 3, 1199.

(1934. Das Beriberi-Herz : Morphologie, Klinik, Pathogenese. Julius Springer, Berlin. Wilkinson, J. F., and Rowlands, E. N. (1938). Brit. Med. J., $2,878$.

Yudkin, J. (1938). Lancet, 2, 1347. 